\title{
Interdisciplinary intervention decreases cognitive impairment for older Taiwanese with hip fracture: 2-year follow-up
}

Yea-Ing L. Shyu ${ }^{1,2 \dagger}$, Ming-Yueh Tseng ${ }^{3,4 \dagger}$, Jersey Liang ${ }^{5,6}$, Wen-Che Tsai ${ }^{7,8,9}$, Chi-Chuan $\mathrm{Wu}^{10}$ and Huey-Shinn Cheng ${ }^{11}$

${ }^{1}$ School of Nursing, College of Medicine, Chang Gung University, Taoyuan, Taiwan

${ }^{2}$ Healthy Aging Research Center, Chang Gung University, Taoyuan, Taiwan

${ }^{3}$ Graduate Institute of Clinical Medical Sciences, Chang Gung University, Taoyuan, Taiwan

${ }^{4}$ Department of Nursing, MeiHo University, Pingtung, Taiwan

${ }^{5}$ School of Public Health, University of Michigan, Ann Arbor, MI, USA

${ }^{6}$ Institute of Gerontology, University of Michigan, Ann Arbor, MI, USA

${ }^{7}$ Department of Psychiatry, National Taiwan University Hospital, Taipei, Taiwan

${ }^{8}$ College of Medicine, National Taiwan University, Taipei, Taiwan

${ }^{9}$ Graduate Institute of Epidemiology and Preventive Medicine, College of Public Health, National Taiwan University Hospital, Taipei, Taiwan

${ }^{10}$ Traumatological Division, Department of Orthopedics, Chang Gung Memorial Hospital, Taoyuan, Taiwan

${ }^{11}$ Department of Internal Medicine, Chang Gung Memorial Hospital, Taoyuan, Taiwan

Correspondence to: J. Liang. E-mail: jliang@umich.edu

${ }^{\dagger}$ Yea-Ing L. Shyu and Ming-Yueh Tseng contributed equally to this work.

Objectives: Few studies describe the trajectories of cognitive function for hip-fracture patients following hospital discharge and the treatment effects of interdisciplinary intervention on cognitive outcomes. The purpose of this study was to explore the 2-year postoperative trajectory for cognitive function of older hip-fracture patients and cognitive effects of an interdisciplinary intervention.

Methods: Of 160 subjects randomly assigned to groups, $29(35.8 \%)$ in the control group $(n=81)$ and 30 $(38.0 \%)$ in the intervention group $(n=79)$ were cognitively impaired at admission. The intervention group received geriatric consultation, continuous rehabilitation, and discharge planning. Subjects' cognitive function was measured using the mini mental state examination Taiwan version at admission, $6,12,18$, and 24 months after discharge and analyzed using hierarchical generalized linear models.

Results: Patients who received the intervention program had $75 \%$ less likelihood of being cognitively impaired 6 months following discharge than those who received routine care (odds ratio $=0.25, p<0.001$ ). The difference between the control and intervention groups was small at admission, peaked at 18 months, and decreased from 18 to 24 months following discharge.

Conclusions: Our interdisciplinary intervention improved the long-term postoperative cognitive functioning of older persons with hip fracture in Taiwan. Copyright (C) 2013 John Wiley \& Sons, Ltd.

Key words: hip fracture; cognitive function; interdisciplinary intervention; older persons

History: Received 17 May 2012; Accepted 22 January 2013; Published online 16 March 2013 in Wiley Online Library

(wileyonlinelibrary.com)

DOI: 10.1002 /gps.3945

\section{Introduction}

Cognitive impairment, which occurs in $31-88 \%$ of postoperative older persons with hip fracture (Holmes and House, 2000a, 2000b), has been found to predict poor functional recovery and to increase risk of mortality (Heruti et al., 1999; Holmes and House, 2000b; Nightingale et al., 2001; Clague et al., 2002; Gruber-Baldini et al., 2003). However, most of these studies investigated the cognitive functioning 
of hip-fracture patients within the first week after surgery and mostly during hospitalization. More long-term cognitive functioning of these patients has been examined in only a few studies. These study findings indicate that cognitive impairment not only occurs during the immediate postoperative period but also persists during the first year following hip fracture. For example, one study found that patients who received total hip arthroplasty developed a significant degree of cognitive impairment during the first year following hospital discharge (Haentjens et al., 2005). In another study, older adults' postoperative cognitive function remained impaired at 12 months (47.8\%) following the fracture, and the persistence of cognitive impairment predicted poor recovery (Gruber-Baldini et al., 2003). However, these studies mostly focused on changes between two points and did not describe the level and rate of change in conjunction with the shape of change over time in cognitive functioning. Timing of cognitive impairment is important to investigate in studies of hip-fracture patients to understand the etiology of their cognitive impairment and its potential treatment (Gruber-Baldini et al., 2003). Furthermore, most of the aforementioned studies were conducted in developed countries, and little is known about postoperative cognitive function of hip-fracture older persons in Asian countries.

An interdisciplinary intervention program in Taiwan improved health and functional outcomes of older persons with hip fracture (Shyu et al., 2010) and also on hip-fractured patients with cognitive impairment (Shyu et al., 2012).However, that clinical trial did not explore treatment effects on the cognitive functioning outcome of these older persons with hip fracture. Unlike prior studies that primarily focused on physical recovery, current focused on describing the trajectories of postoperative cognitive functioning of older persons with hip fracture and on exploring the effects of interdisciplinary intervention on cognitive functioning.

Postoperative cognitive dysfunction in hip-fracture older persons was found to have a clear tendency for time-related improvement (Bodolea et al., 2008), and cognitive impairment was found to persist up to 2 years after hip fracture (Samuelsson et al., 2009). Thus, the purposes of this study were to investigate the following: (1) the 2-year trajectory of recovery from cognitive impairment, not only the linear function but also quadratic and cubic functions, (2) the effects of an interdisciplinary intervention on the level and speed of change in cognitive function, and (3) the effect of at-admission (preoperative) cognitive function on the cognitive function trajectory.

\section{Methods}

\section{Design and data}

Data for the present study came from the 2-year follow-up of a clinical trial examining the effectiveness of an interdisciplinary intervention program for older persons with hip fracture (Shyu et al., 2010). Of the 162 subjects ( 82 in the control group and 80 in the intervention group), 160 completed at-admission assessment of cognitive function, and their data were used for the current study. Of 160 subjects randomly assigned to groups, $29(35.8 \%)$ in the control group $(n=81)$ and $30(38.0 \%)$ in the intervention group $(n=79)$ were cognitively impaired at admission. The majority of participants completed the follow-ups at $12(n=121,75.6 \% ; 60$ and 61 in the intervention and control groups, respectively) and 24 months ( $n=103,64.4 \%$; 55 and 48 in the intervention and control groups, respectively).

Patients were included in the study if they met these criteria: (1) age 60 years or older; (2) admitted to hospital for an accidental single-side hip fracture; (3) receiving hip arthroplasty or internal fixation; (4) able to perform full range of motion against gravity and against some or full resistance and have a prefracture Chinese Barthel Index score $>70$; and (5) living in northern Taiwan. Patients were excluded if they were (1) severely cognitively impaired, making them unable to follow orders (score $<10$ on the mini-mental state examination [MMSE], Taiwan version) (Yip et al., 1997), or (2) terminally ill.

\section{Intervention program and usual care}

The interdisciplinary intervention program included geriatric consultation services, a continuous rehabilitation program, and discharge-planning services and lasted until 3 months after discharge (Shyu et al., 2005; Shyu et al., 2008). The geriatric assessment/ consultation was administered by a geriatrician and geriatric nurses during hospitalization, before and after surgery to detect potential medical and functional problems and to decrease delays before surgery. Continuous rehabilitation included inpatient and athome programs and was delivered by geriatric nurses and physical therapists to provide early postoperative rehabilitation, facilitate mobility, and provide rehabilitation in the patient's usual environment. Both in- 
hospital and at-home rehabilitation programs included a hip fracture-oriented intervention and a fitnessenhancing intervention. The hip fracture-oriented rehabilitation emphasized pain relief, range of motion, muscle strength and endurance, proprioceptive enhancement, and balance challenges. The exercise protocol was individualized according to each patient's condition and progressed from ankle dorsiflexion with knee extension, isometric full knee extension, gently bouncing vertical jump with knee semiflexed and foot on the floor, and ball-rolling activities to enhance proprioception. The discharge-planning component was delivered by geriatric nurses of the interdisciplinary team to maintain continuity of care and to make appropriate referrals. The geriatric nurses also assessed the home environment, made suggestions regarding environmental modifications, and monitored clinical follow-up adherence. Subjects in the control group received usual care that does not include geriatric assessment, in-home rehabilitation, and individualized discharge planning with discharge telephone follow-up and home environment assessment.

\section{Procedures}

Before data were collected from subjects, the study was approved by the hospital's institutional review board. Subjects were recruited from the emergency department by research nurses. Those who agreed to participate were randomly assigned to either an intervention or control group. Subjects in the intervention group received routine hospital care plus the intervention program, and subjects in the control group received only routine hospital care plus regular social contact provided by a research nurse at the same time that the intervention group received the intervention. Subjects' cognitive function was assessed by the research nurses at admission as well as $6,12,18$, and 24 months following discharge.

\section{Measurements}

Subjects' cognitive function was measured using the MMSE Taiwan version (Folstein et al., 1975; Yip et al., 1992). The MMSE was chosen after a systematic review found that it has been used in many studies to measure cognitive impairment following hip fracture (Holmes and House, 2000a). The 11-item MMSE assesses subjects' orientation, memory, common sense, ability to use language, construction ability, as well as content of thought, form, and process (Folstein et al.,
1975). Total scores range from 0 to 30 , with higher scores indicating better cognitive function. The MMSE was used as a screening instrument to determine subjects' cognitive status at admission, that is, whether they had cognitive impairment before surgery. Preoperative cognitive performance has been used as a baseline measure to detect postoperative cognitive decline (Bodolea et al., 2008). Subjects were categorized as cognitively impaired if they had $<6$ years of education and their MMSE score was $<21$ or if they had $\geq 6$ years of education and their MMSE score was $<25$ (Yip et al., 1992). In this study, patients' cognitive function was assessed by a geriatric nurse in faceto-face interviews using the MMSE at the hospital for baseline assessment and during home visits for follow-up assessments. In addition to treatment group and baseline MMSE score, age, gender, and education were treated as covariates.

\section{Statistical analysis}

Changes in cognitive functioning were analyzed by hierarchical generalized linear models (Raudenbush and Bryk, 2002). Because MMSE scores exhibited a skew distribution, cognitive function was treated as a binary variable (1, cognitively impaired; 0 , not cognitively impaired). On the basis of repeated observations within subjects, we modeled the log-odds of an individual being cognitively impaired relative to not being cognitively impaired as a function of time since baseline (i.e., hospital admission) in the following equation:

$$
\ln \left(p_{i j} / 1-p_{i j}\right)=\pi_{0 i}+\pi_{1 i} \operatorname{Time}_{i j}+E_{i j}
$$

where $p_{i j}$ is the probability of individual $i$ being cognitively impaired at time $j$. Time $e_{i j}$ measures the number of months of follow-up since hospital admission. $\pi_{0 i}$ and $\pi_{1 i}$, respectively, are the intercept and rate of change (i.e., linear slope) in the log-odds of individual $i$ being cognitively impaired over time. $E_{i j}$ is a random error. We also explored nonlinear changes with time by incorporating a quadratic term of the time variable (e.g., Time $e_{i j}^{2}$ ) in Equation (1). When evaluating nonlinear changes with time, we centered time at 6 months after discharge to minimize the possibility of multicollinearity.

To explore the effects of the interdisciplinary intervention and preoperative cognitive status on the level of cognitive functioning $\left(\pi_{0 i}\right)$ and its rate of change over time $\left(\pi_{1 i}\right)$, we used the following equations.

$$
\pi_{0 i}=\beta_{00}+\Sigma\left(\beta_{0 q} Z_{q i}\right)+r_{0 i}
$$




$$
\pi_{1 i}=\beta_{10}+\Sigma\left(\beta_{1 q} Z_{q i}\right)+r_{1 i}
$$

where $\beta_{0 q}$ and $\beta_{1 q}$, respectively, represent the effects of the qth covariate (e.g., age, gender, education, and the intervention program) on the log-odds of being cognitively impaired and its rate of change for individual i. $r_{0 i}$ and $r_{1 i}$ are random effects with a mean of 0 . Finally, the effect of attrition was controlled by including two dummy variables, which identified participants who died during the 2-year follow-up period and those who dropped out for other reasons.

\section{Results}

The odds of cognitive impairment follows a quadratic trajectory

The intervention group and control groups did not differ significantly at baseline in age, gender, marital status, education background, number of co-morbidities, type of fracture and surgery, time before surgery, American Society of Anesthesiologists rating, pre-fracture Chinese Barthel Index score, and length of hospital stay (Shyu et al., 2010). In our analysis, subjects' baseline characteristics were treated as baseline covariates (Table 1). These subjects were all community dwelling and returned to the community after discharge. The odds of being cognitively impaired decreased, approximated by a quadratic trajectory (model 1 in Table 2). The decrease in cognitive impairment was offset by a positive curvature or quadratic slope with time $(b=0.004$, odds ratio $[\mathrm{OR}]=1.004,95 \%$ confidence interval $[\mathrm{CI}]=1.001-$ $1.007, p<0.05)$. Figure $1(\mathrm{~A})$ shows the probability of being cognitively impaired over time. In particular, it decreased during the first year but increased during the second year.

\section{Cognitive function trajectory of intervention group is better than that of control group}

The interdisciplinary intervention significantly influenced the postoperative trajectory of cognitive functioning. In particular, subjects who received the intervention program were $75 \%$ less likely to be cognitively impaired

Table 1 Comparison of subjects' characteristics and covariates by group $(N=160)$

\begin{tabular}{|c|c|c|c|c|}
\hline Characteristic & Total $(n=160)$ & Intervention group $(n=79)$ & Control group $(n=81)$ & $p^{*}$ \\
\hline Age, mean (SD), years & $78.19(7.80)$ & $77.38(8.24)$ & $78.98(7.31)$ & 0.197 \\
\hline Gender, $n(\%)$ & & & & 1.00 \\
\hline Male & $50(31.3)$ & 25(31.6) & 25(31.6) & \\
\hline Female & $110(68.8)$ & $54(68.4)$ & $56(69.1)$ & \\
\hline \multicolumn{5}{|l|}{ Marital status, $n(\%)$} \\
\hline Married & $83(51.9)$ & $37(46.8)$ & $46(56.8)$ & 0.350 \\
\hline Widowed & $75(46.9)$ & $40(50.6)$ & $35(43.2)$ & \\
\hline Other & $2(1.2)$ & $2(2.6)$ & $0(0)$ & \\
\hline Educational background, $n$ (\%) & & & & 0.732 \\
\hline Illiterate & $78(48.8)$ & $40(50.6)$ & $38(46.9)$ & \\
\hline Primary school & $51(31.9)$ & $22(27.8)$ & $29(35.8)$ & \\
\hline High school & 18(11.3) & $10(12.7)$ & $8(9.9)$ & \\
\hline College or above & $13(8.1)$ & $7(8.9)$ & $6(7.4)$ & \\
\hline \multicolumn{5}{|c|}{ Baseline cognitive status (MMSE score), $n$ (\%) } \\
\hline $10-14$ & $10(6.2)$ & $4(5.1)$ & $6(7.4)$ & 0.567 \\
\hline $15-19$ & $30(18.8)$ & $18(22.8)$ & $12(14.8)$ & \\
\hline $20-24$ & $40(25.0)$ & $20(25.3)$ & $20(24.7)$ & \\
\hline $25-30$ & $80(50.0)$ & $37(46.8)$ & $43(53.1)$ & \\
\hline \multicolumn{5}{|l|}{ Death, $n(\%)$} \\
\hline Month 6 & $5(3.1)$ & 1(1.3) & $4(4.9)$ & 0.367 \\
\hline Month 12 & $10(6.3)$ & $4(5.1)$ & $6(7.4)$ & 0.746 \\
\hline Month 18 & $17(10.6)$ & $7(8.9)$ & $10(12.3)$ & 0.610 \\
\hline Month 24 & $22(13.8)$ & $9(11.4)$ & 13(16.0) & 0.493 \\
\hline \multicolumn{5}{|l|}{ Dropped out, $n$ (\%) } \\
\hline Month 6 & $24(15.0)$ & $13(16.5)$ & 11(13.6) & 0.662 \\
\hline Month 12 & $29(18.1)$ & $15(19.0)$ & $14(17.3)$ & 0.839 \\
\hline Month 18 & $31(19.4)$ & 15(19.0) & $16(19.8)$ & 1.00 \\
\hline Month 24 & $35(21.9)$ & $15(19.0)$ & $20(24.7)$ & 0.446 \\
\hline
\end{tabular}

SD, standard deviation; MMSE, mini mental state examination.

${ }^{*} p$ determined by independent-samples $t$-test or chi-square test. 
Table 2 Intrapersonal and interpersonal differences in postoperative cognitive function for older persons with hip fracture

\begin{tabular}{|c|c|c|c|c|}
\hline \multirow[b]{2}{*}{ Variable } & \multicolumn{2}{|c|}{ Model 1} & \multicolumn{2}{|c|}{ Model 2} \\
\hline & Coefficient & OR $(95 \% \mathrm{Cl})$ & Coefficient & OR $(95 \% \mathrm{Cl})$ \\
\hline \multicolumn{5}{|l|}{ Fixed effect } \\
\hline \multicolumn{5}{|l|}{ For intercept $\left(\pi_{0}\right)$} \\
\hline Intercept (at 6 months) & $-1.11^{\star \star \star}$ & $0.33(0.22-0.49)$ & $-1.35^{\star \star}$ & $0.26(0.11-0.59)$ \\
\hline Ever dropped out & & & 0.07 & $1.06(0.03-33.95)$ \\
\hline Death & & & $1.46^{*}$ & $4.30(1.13-16.43)$ \\
\hline Intervention group & & & $-1.40^{\star \star \star}$ & $0.25(0.11-0.56)$ \\
\hline At-admission cognitive impairment & & & $3.61^{\star \star \star}$ & 36.81 (13.59-99.68) \\
\hline Age & & & $0.09^{\star \star}$ & $1.09(1.03-1.16)$ \\
\hline Male & & & -0.19 & $0.83(0.34-2.02)$ \\
\hline$\geq$ Primary school & & & -0.35 & $0.70(0.27-1.84)$ \\
\hline \multicolumn{5}{|l|}{ For linear time slope $\left(\pi_{1}\right)$} \\
\hline Intercept & $-0.06^{*}$ & $0.95(0.91-0.99)$ & -0.05 & $0.95(0.88-1.03)$ \\
\hline Ever dropped out & & & 0.10 & $1.10(0.80-1.53)$ \\
\hline Death & & & 0.07 & $1.07(0.87-1.31)$ \\
\hline Intervention group & & & -0.11 & $0.89(0.80-1.00)$ \\
\hline At-admission cognitive impairment & & & $-0.42^{\star \star \star}$ & $0.66(0.57-0.75)$ \\
\hline Age & & & 0.004 & $1.00(0.99-1.01)$ \\
\hline Male & & & 0.14 & $1.14(0.98-1.34)$ \\
\hline$\geq$ Primary school & & & $-0.24^{\star \star \star}$ & $0.78(0.68-0.90)$ \\
\hline \multicolumn{5}{|l|}{ For quadratic time slope $\left(\pi_{2}\right)$} \\
\hline Intercept & $0.004^{*}$ & $1.004(1.001-1.007)$ & 0.01 & $1.01(0.99-1.02)$ \\
\hline Ever dropped out & & & 0.02 & $1.02(0.97-1.07)$ \\
\hline Death & & & 0.004 & $1.00(0.99-1.02)$ \\
\hline Intervention group & & & $0.01^{*}$ & $1.01(1.00-1.02)$ \\
\hline At-admission cognitive impairment & & & $0.02^{\star \star \star}$ & $1.02(1.01-1.04)$ \\
\hline Age & & & 0.000 & $1.00(0.99-1.00)$ \\
\hline Male & & & -0.01 & $0.99(0.98-1.00)$ \\
\hline$\geq$ Primary school & & & $0.02^{\star \star}$ & $1.02(1.01-1.03)$ \\
\hline \multicolumn{5}{|l|}{ Random effect } \\
\hline Intercept & $2.84^{\star \star \star}$ & & 1.57 & \\
\hline Linear time slope & 0.002 & & 0.010 & \\
\hline Quadratic time slope & 0.000 & & 0.000 & \\
\hline
\end{tabular}

OR, odds ratio; $95 \%$ CI, 95\% confidence interval.

${ }^{*} p<0.05,{ }^{* *} p<0.01,{ }^{* * *} p<0.001$.

6 months following discharge than those who received usual care $(b=-1.40, \mathrm{OR}=0.25,95 \% \mathrm{CI}=0.11-0.56$, $p<0.001$; model 2 in Table 2$)$. The probability of cognitive impairment in the control group was higher than in the intervention group, and the difference between groups increased before 18 months after discharge but decreased thereafter (Figure 1(B)). The treatment effect on decreasing cognitive impairment was greater within 18 months following discharge. For subjects in the intervention group, the probability of being cognitively impaired decreased from 0.26 to 0.05 during the first 12 months after discharge, remained low, then increased at an accelerating rate (from 0.13 to 0.66 ) between 18 and 24 months after discharge. On the other hand, for subjects in the control group, the probability of being cognitively impaired decreased from 0.34 to 0.21 during the first 6 months after discharge and then increased in an accelerating fashion to 0.75 during the following 24 months.
Odds of cognitive impairment after discharge is influenced by cognitive status at admission

The odds of cognitive impairment during the 24-month period after discharge were substantially influenced by cognitive functioning at admission. Subjects who were cognitively impaired at admission were 36.81 times more likely than cognitively intact subjects to have impaired cognitive functioning 6 months after discharge $(b=3.61, \mathrm{OR}=36.81,95 \% \mathrm{CI}=13.59-99.68, p<0.001$; model 2 in Table 2). The linear rate of change in the odds of cognitive impairment was lower among subjects who were cognitively impaired at admission than among those who were cognitively intact $(b=-0.42$, $\mathrm{OR}=0.66,95 \% \mathrm{CI}=0.57-0.75, p<0.001)$. However, the curvature or quadratic rate of change in the odds of cognitive impairment was significantly higher for those with cognitive impairment at admission $(b=0.02, \mathrm{OR}=1.02,95 \% \mathrm{CI}=1.01-1.04, p<0.001)$. 
(A)
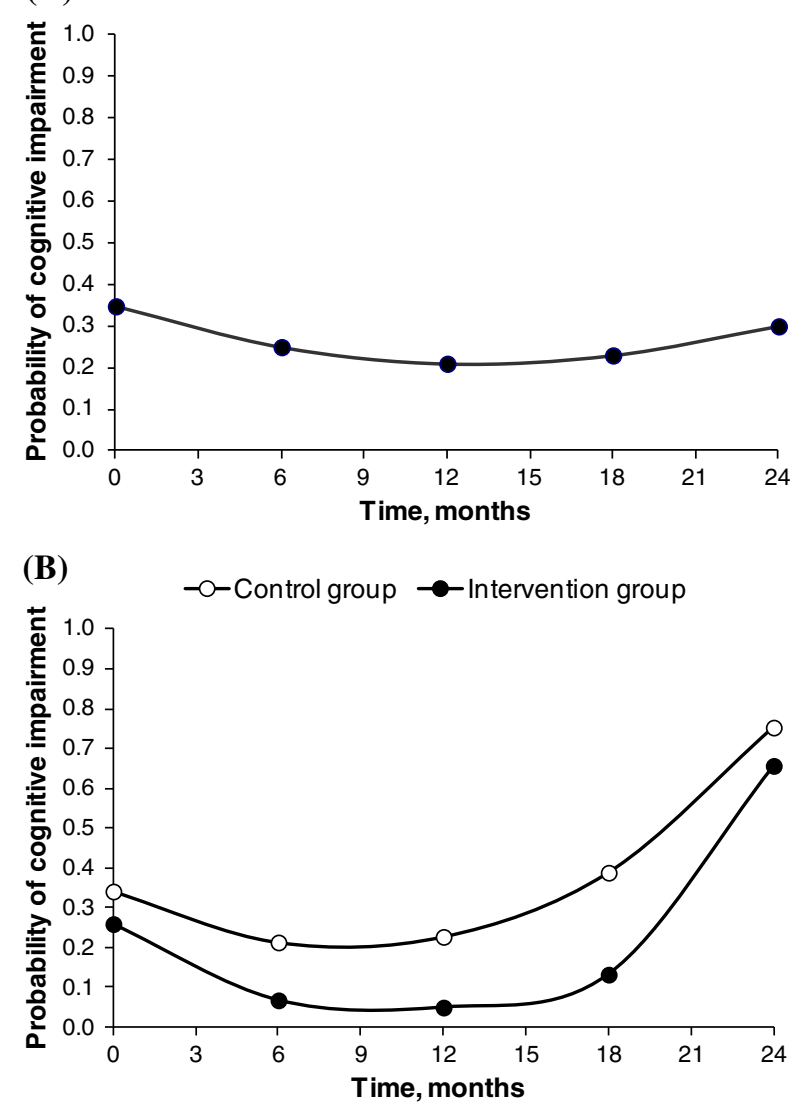

(C) $\rightarrow$ Cognitively intact $\rightarrow-$ Cognitively impaired

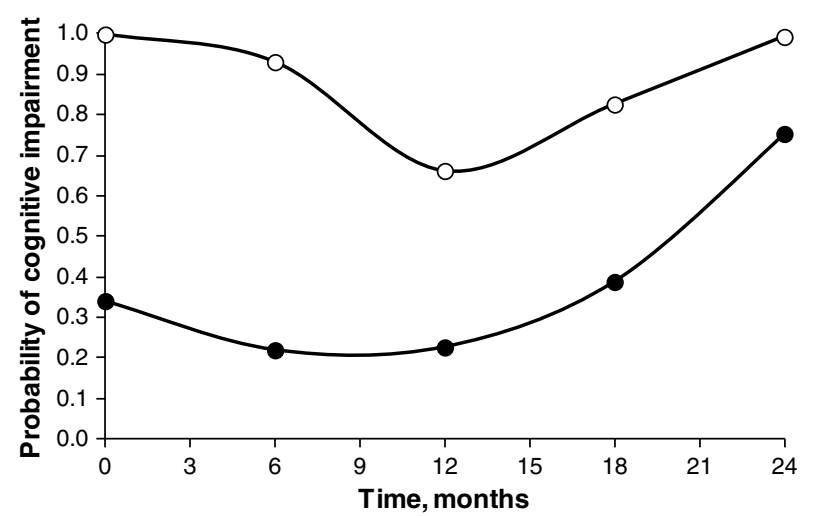

Figure 1 (A) Changes in cognitive impairment over time by model 1, (B) postoperative cognitive function by treatment group based on the final model (model 2), and (C) postoperative cognitive function by at-admission cognitive status based on the final model (model 2).

The difference in cognitive impairment between those with and without baseline or at-admission cognitive impairment was large but decreased significantly during the first year after discharge. This difference continued to narrow but at a more moderate rate from
12 to 24 months following discharge (Figure 1(C)). Throughout the 2-year follow-up, the predicted probability of being cognitively impaired for those with at-admission cognitive impairment decreased from 1.00 to 0.66 during the first 12 months and then increased from 0.66 to 0.99 from 12 to 24 months following discharge. During the same period, the probability of cognitive impairment was much lower for subjects without at-admission cognitive impairment. These subjects' probability decreased during the first 12 months from 0.34 to 0.23 but increased from 12 to 24 months to 0.75 .

\section{Odds of being cognitively impaired after discharge with} adjustment for covariates

The odds of being cognitively impaired during the 24 months after discharge were also significantly associated with the intervention effects, education, age, and at-admission cognitive status (model 2 in Table 2). However, even when age, gender, and education were adjusted, the effects of intervention and cognitive status at admission remained robust.

To control for potential confounding with the effects of randomized intervention, we included measures of mortality and dropout in model 2 . The likelihood of having cognitive impairment at 6 months following discharge was 4.3 times greater for those who died than those who survived during the 2-year follow-up $(b=1.46, \mathrm{OR}=4.30,95 \% \mathrm{CI}=1.13-16.43$, $p<0.05$; model 2 in Table 2). However, the decedents and survivors did not differ significantly in their linear and quadratic rates of change in the odds of being cognitively impaired. Furthermore, the level and rate of change in the odds of being cognitively impaired were not associated with dropout (model 2 in Table 2).

We have tested the intervention effect by initial cognitive status-group interaction in model 3 (Appendix A). As shown in Figure A1, the effect of the intervention differs depending on the initial cognitive status. Among those who were cognitively impaired at baseline, the intervention effect increased between discharge and 12 months afterwards. During the next 12 months, however, the intervention effect began to diminish, and the levels of cognitive impairment eventually converged at month 24. In contrast, among those who were not cognitively impaired, the treatment effect remained robust and even increased slightly throughout the 24-month period. 
- Intervention group with cognitive impairment

- -O-- Intervention group without cognitive impairment

$\longrightarrow$ Control group with cognitive impairment

$--\triangle-$ - Control group without cognitive impairment

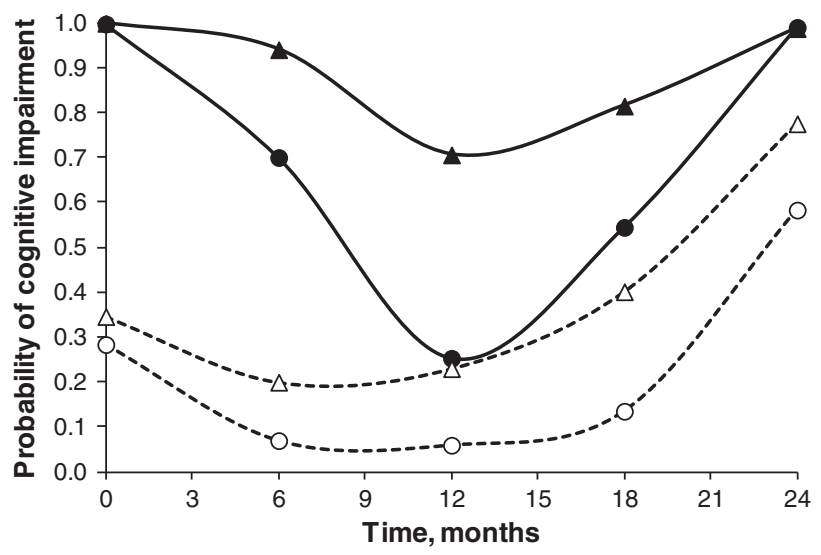

Figure A1 Intervention by initial cognitive status-group interaction effect based on model 3 in Appendix A.

\section{Discussion}

This study contributes to current understanding of recovery from hip fracture in several ways. First, the results quantitatively depict the long-term trajectory of postoperative cognitive function among older patients with hip fracture. We found that changes in the odds of cognitive impairment during the first 2 years following discharge can be approximated by a quadratic function. Regardless of at-admission cognitive status, patients' probability of cognitive impairment decreased during the first 6 months following discharge and remained relatively stable until 12 months, although some older patients have been reported to have cognitive impairment 1 year following hip fracture (Gruber-Baldini et al., 2003; Haentjens et al., 2005).

We also found that the chance of cognitive impairment for the whole sample increased during the second year following discharge. This result differs from that of a previous study that also used MMSE scores to assess cognitive function in 547 communitydwelling older persons 70 years and older (Royall et al., 2004). In that study, cognitive impairment did not increase during the 3 years of observation; indeed, the mean MMSE scores were relatively stable (Royall et al., 2004). The difference between that study and ours might be due to the impact of hip fracture, that is, the decline in cognitive function might be more severe during the second year after discharge for older persons with hip fracture than for community-dwelling older persons without hip fracture. This possibility needs to be further explored.
Second, this study shows that the interdisciplinary intervention reduced the risk for cognitive impairment in addition to recovering physical function (Shyu et al., 2010) and the cognitive benefits were maintained for up to 2 years after discharge. The intervention effect on reducing cognitive impairment increased during the first year and reached its maximum at 18 months but decreased from the 18th month to 2 years after discharge. Although the interdisciplinary intervention did not target cognitive function, it might have indirectly enhanced postoperative cognitive function by improving physical function, which has been associated with cognitive status (Milisen et al., 1998; Plehn et al., 2004).

Third, this study found that at-admission cognitive status influenced the trajectory of risk for postoperative cognitive impairment for 2 years after discharge. This result is consistent with a previous report that the presence of preoperative cognitive impairment in older persons with hip fracture strongly predicted postoperative impairment (MMSE scores) at 2 and 12 months (Gruber-Baldini et al., 2003). Further studies are needed to explore whether the higher chance of cognitive impairment for those with at-admission cognitive impairment is associated with prior neuronal depopulation or by functional impairment of neuronal pathways (Maze et al., 2008). We also analyzed the trajectories by treating MMSE score as a continuous variable and found similar results (Appendix B and Figure B1). Subjects who received the intervention program had better cognitive function (higher MMSE scores) than those who received usual care. In addition, subjects who were cognitively impaired at admission had poorer cognitive function (lower MMSE scores) than those who were cognitively intact at admission.

The trajectory was approximated by a quadratic function. Our criteria for selecting subjects excluded older persons with severe cognitive impairment. Thus, our sample may have had better cognitive function than the general population of older persons with hip fracture in Taiwan. The results of this study can therefore only be generalized for hip-fracture older persons without severe cognitive impairment. Another limitation of our study was the lack of a comparison group without hip fracture; thus, cognitive trajectories could not be compared between older persons with and without hip fracture. Furthermore, we did not collect data on Alzheimer's and related dementia diagnoses prior to hip fracture or on delirium diagnosed in the hospital, although pre-existing cognitive impairment is a risk factor for postoperative delirium (Deiner and Silverstein, 2009), and delirium was the main predictor of dementia 6 months after hip fracture 
(A)

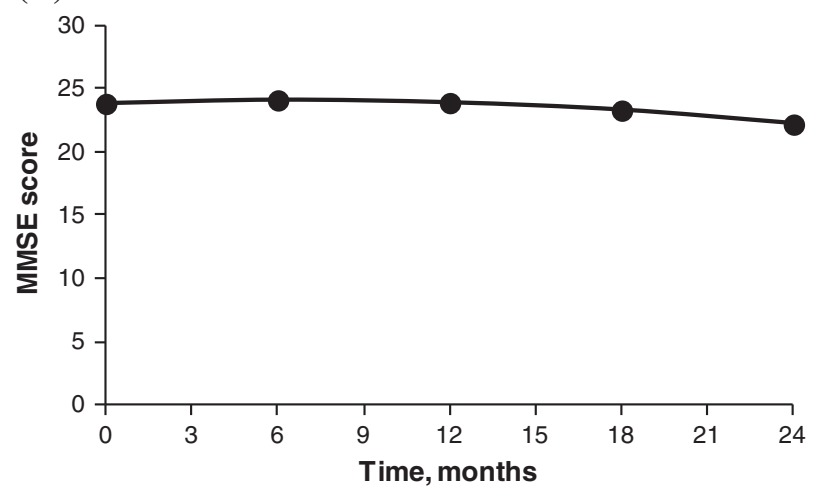

(B)

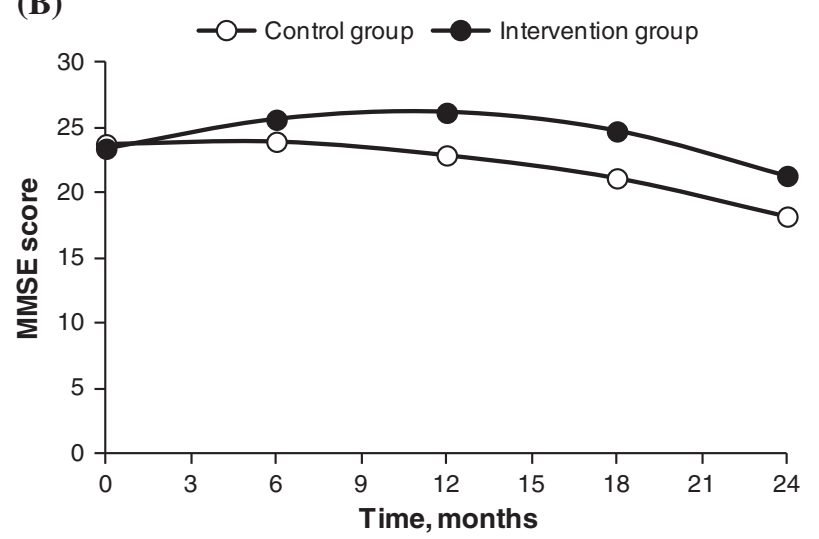

(C)

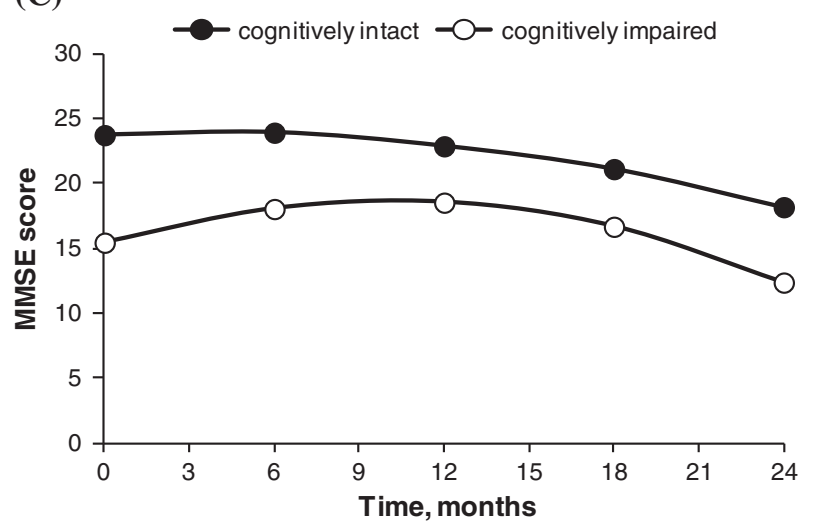

Figure B1 (A) Changes in cognitive impairment over time by model 1 in Appendix B, (B) postoperative cognitive function by treatment group based on model 2 in Appendix B, and (C) postoperative cognitive function by at-admission cognitive status based on model 2 in Appendix B.

(Krogseth et al., 2011). The generalizability of our findings might also have been limited by using a single study site. Nonetheless, our sample was quite similar to that of another study conducted in central Taiwan on older persons with hip fracture (Wong et al., 2008). A final limitation of this study was that dementia and delirium were not differentiated.
In conclusion, despite this study's limitations, our interdisciplinary intervention benefited the postoperative cognitive function of older Taiwanese with hip fracture for 2 years following discharge. These study results indicate that this patient population needs to be clinically assessed and managed for postoperative cognitive impairment for at least 2 years following discharge. Specific attention needs to be paid to older persons with at-admission cognitive impairment. We suggest that future studies include assessments of both cognitive impairment and psychological status in detail and clinically differentiate between delirium and dementia.

\section{Acknowledgement}

This work was supported by a grant from the National Health Research Institute (grant number NHRI-EX929023PL), Taiwan.

\section{Conflict of interest}

None declared.

\section{Key points}

- The odds of cognitive impairment during the first 2 years following discharge can be approximated by a quadratic function.

- The interdisciplinary intervention benefited the postoperative cognitive function of elderly Taiwanese with hip fracture for 2 years following discharge.

- At-admission cognitive status influenced the trajectory of risk for postoperative cognitive impairment for 2 years after discharge.

\section{References}

Bodolea C, Hagau N, Coman I, et al. 2008. Postoperative cognitive dysfunction in elderly patients: an integrated psychological and medical approach. J Cogn Behav Psychother 8: 117-132.

Clague JE, Craddock E, Andrew G, Horan MA, Pendleton N. 2002. Predictors of outcome following hip fracture. Admission time predicts length of stay and inhospital mortality. Injury 33: 1-6.

Deiner S, Silverstein JH. 2009. Postoperative delirium and cognitive dysfunction. $\mathrm{Br} \mathrm{J}$ Anaesth 103: i41-i46. DOI: 10.1093/bja/aep291

Folstein MF, Folstein SE, McHugh PR. 1975. "Mini-mental state". A practical method for grading the cognitive state of patients for the clinician. J Psychiatr Res 12: 189-198. DOI: 10.1016/0022-3956(75)90026-6

Gruber-Baldini AL, Zimmerman S, Morrison RS, et al. 2003. Cognitive impairment in hip fracture patients: timing of detection and longitudinal follow-up. J Am Geriatr Soc 51: 1227-1236. DOI: 10.1046/j.1532-5415.2003.51406.x 
Haentjens P, Autier P, Barette M, Boonen S. On behalf of the Belgian Hip Fracture Study Group. 2005. Predictors of functional outcome following intracapsular hip fracture in elderly women: a one-year prospective cohort study. Injury 36: 842-850. DOI: 10.1016/j.injury.2005.02.002

Heruti RJ, Lusky A, Barell V, Ohry A, Adunsky A. 1999. Cognitive status at admission: does it affect the rehabilitation outcome of elderly patients with hip fracture? Arch Phys Med Rehabil 80: 432-436. DOI: 10.1016/S0003-9993(99)90281-2

Holmes JD, House AO. 2000a. Psychiatric illness in hip fracture. Age Ageing 29: 537-546. DOI: 10.1093/ageing/29.6.537

Holmes JD, House AO. 2000b. Psychiatric illness predicts poor outcome after surgery for hip fracture: a prospective cohort study. Psychol Med 30: 921-929.

Krogseth M, Wyller TB, Engedal K, Juliebø V. 2011. Delirium is an important predictor of incident dementia among elderly hip fracture patients. Dement Geriatr Cogn Disord 31: 63-70. DOI: 10.1159/000322591

Maze M, Cibelli M, Grocott HP. 2008. Taking the lead in research into postoperative cognitive dysfunction. Anesthesiology 108: 1-2. DOI: 10.1097/01. anes.0000296105.43657.05

Milisen K, Abraham IL, Broos PL. 1998. Postoperative variation in neurocognitive and functional status in elderly hip fracture patients. J Adv Nurs 27: 59-67. DOI: 10.1046/j.1365-2648.1998.00491.x

Nightingale S, Holmes J, Mason J, House A. 2001. Psychiatric illness and mortality after hip fracture. Lancet 357: 1264-1265. DOI: 10.1016/S0140-6736(00)04421-4

Plehn K, Marcopulos BA, McLain CA. 2004. The relationship between neuropsychological test performance, social functioning, and instrumental activities of daily living in a sample of rural older adults. Clin Neuropsychol 18: 101-113. DOI: $10.1080 / 13854040490507190$

Raudenbush SW, Bryk AS. 2002. Hierarchical Linear Models: Applications and Data Analysis Methods. 2nd (Edn). Sage: Newbury Park, CA.
Royall DR, Palmer R, Chiodo LK, Polk MJ. 2004. Declining executive control in normal aging predicts change in functional status: the Freedom House Study. J Am Geriatr Soc 52: 346-352. DOI: 10.1111/j.1532-5415. 2004.52104.x

Samuelsson B, Hedström MI, Ponzer S, et al. 2009. Gender differences and cognitive aspects on functional outcome after hip fracture: a 2 years' follow-up of 2,134 patients. Age Ageing 38: 686-692. DOI: 10.1093/ageing/afp169

Shyu YL, Liang J, Wu CC, et al. 2005. A pilot investigation of the short-term effects of an interdisciplinary intervention program on elderly patients with hip fracture in Taiwan. J Am Geriatr Soc 53: 811-818. DOI: 10.1111/j.15325415.2005.53253.x

Shyu YI, Liang J, Wu CC, et al. 2008. Interdisciplinary intervention for hip fracture in older Taiwanese: benefits last for 1 year. J Gerontol A Biol Sci Med Sci 63: 92-97.

Shyu YIL, Liang J, Wu CC, et al. 2010. Two-year effects of interdisciplinary intervention for hip fracture in older Taiwanese. J Am Geriatr Soc 58: 1081-1089. DOI: 10.1111/j.1532-5415.2010.02882.x

Shyu YI, Tsai WC, Chen MC, et al. 2012. Two-year effects of an interdisciplinary intervention on recovery following hip fracture in older Taiwanese with cognitive impairment. Int J Geriatr Psychiatry 27: 529-538. DOI: 10.1002/gps.2750

Wong CW, Yeh CB, Chou MC, et al. 2008. Epidemiology and medical costs of patients with hip fracture at a medical center in central Taiwan. J Taiwan Emerg Med 10: 81-86.

Yip PK, Shyu YI, Liu SI, et al. 1992. An epidemiological survey of dementia among elderly in an urban district of Taipei. Acta Neuro Sinica 1: 347-354.

Yip PK, Shyu YI, Liu SI, et al. 1997. The multidisciplinary project of dementia study in northern Taiwan (DSNT): background and methodology. Acta Neurol Taiwan 6: $210-216$.

\section{Appendix A}

Intervention by initial cognitive status-group interaction effect (reference group is control group without cognitive impairment)

\begin{tabular}{|c|c|c|c|c|}
\hline \multirow[b]{2}{*}{ Variable } & \multicolumn{2}{|c|}{ Model 1} & \multicolumn{2}{|c|}{ Model 3} \\
\hline & Coefficient & OR $(95 \% \mathrm{Cl})$ & Coefficient & OR $(95 \% \mathrm{Cl})$ \\
\hline \multicolumn{5}{|l|}{ Fixed effect } \\
\hline \multicolumn{5}{|l|}{ For intercept $\left(\pi_{0}\right)$} \\
\hline Intercept (at 6 months) & $-1.11^{\star \star \star}$ & $0.33(0.22-0.49)$ & $-1.34^{\star \star}$ & $0.26(0.11-0.62)$ \\
\hline Ever dropped out & & & -0.04 & $0.96(0.03-34.81)$ \\
\hline Death & & & $1.42^{\star}$ & $4.13(1.09-15.61)$ \\
\hline Age & & & $0.09^{\star *}$ & $1.09(1.03-1.16)$ \\
\hline Male & & & -0.29 & $0.75(0.29-1.90)$ \\
\hline$\geq$ Primary school & & & -0.33 & $0.72(0.28-1.85)$ \\
\hline Intervention group with cognitive impairment & & & $2.14^{\star \star}$ & $8.47(2.61-27.50)$ \\
\hline Intervention group without cognitive impairment & & & $-1.16^{\star}$ & $0.31(0.11-0.90)$ \\
\hline Control group with cognitive impairment & & & $3.96^{\star \star \star}$ & $52.52(12.31-224.09)$ \\
\hline \multicolumn{5}{|l|}{ For linear time slope $\left(\pi_{1}\right)$} \\
\hline Intercept & $-0.06^{*}$ & $0.95(0.91-0.99)$ & -0.05 & $0.95(0.87-1.03)$ \\
\hline Ever dropped out & & & 0.09 & $1.10(0.79-1.54)$ \\
\hline Death & & & 0.06 & $1.07(0.87-1.31)$ \\
\hline Age & & & 0.004 & $1.00(0.99-1.01)$ \\
\hline Male & & & 0.13 & $1.14(0.96-1.36)$ \\
\hline$\geq$ Primary school & & & $-0.24^{\star \star}$ & $0.78(0.69-0.90)$ \\
\hline Intervention group with cognitive impairment & & & $-0.53^{\star \star \star}$ & $0.59(0.49-0.70)$ \\
\hline Intervention group without cognitive impairment & & & -0.10 & $0.90(0.78-1.05)$ \\
\hline Control group with cognitive impairment & & & $-0.43^{\star \star \star}$ & $0.65(0.53-0.80)$ \\
\hline \multicolumn{5}{|l|}{ For quadratic time slope $\left(\pi_{2}\right)$} \\
\hline Intercept & $0.004^{*}$ & $1.004(1.001-1.007)$ & 0.01 & $1.01(0.99-1.02)$ \\
\hline Ever dropped out & & & 0.02 & $1.02(0.97-1.08)$ \\
\hline Death & & & 0.005 & $1.01(0.98-1.03)$ \\
\hline Age & & & 0.000 & $1.00(0.99-1.00)$ \\
\hline Male & & & -0.01 & $0.99(0.98-1.00)$ \\
\hline
\end{tabular}

(Continues) 
(Continued)

\begin{tabular}{|c|c|c|c|c|}
\hline \multirow[b]{2}{*}{ Variable } & \multicolumn{2}{|c|}{ Model 1} & \multicolumn{2}{|c|}{ Model 3} \\
\hline & Coefficient & OR $(95 \% \mathrm{Cl})$ & Coefficient & OR (95\% Cl) \\
\hline$\geq$ Primary school & & & $0.02^{\star \star}$ & $1.02(1.01-1.03)$ \\
\hline Intervention group with cognitive impairment & & & $0.03^{\star \star \star}$ & $1.03(1.02-1.05)$ \\
\hline Intervention group without cognitive impairment & & & 0.01 & $1.01(0.99-1.02)$ \\
\hline Control group with cognitive impairment & & & $0.02^{\star \star}$ & $1.02(1.01-1.04)$ \\
\hline Random effect & & & & \\
\hline Intercept & $2.84^{\star \star \star}$ & & 1.61 & \\
\hline Linear time slope & 0.002 & & 0.01 & \\
\hline Quadratic time slope & 0.000 & & 0.000 & \\
\hline
\end{tabular}

Notes: OR, odds ratio; $95 \%$ CI, $95 \%$ confidence interval.

${ }^{*} p<0.05,{ }^{* *} p<0.01,{ }^{* * *} p<0.001$.

\section{Appendix B}

Intrapersonal and interpersonal differences in postoperative cognitive function for older persons with hip fracture $(N=160)$

\begin{tabular}{|c|c|c|}
\hline & Model 1 & Model 2 \\
\hline Variable & Coefficient & Coefficient \\
\hline \multicolumn{3}{|l|}{ Fixed effect } \\
\hline \multicolumn{3}{|l|}{ For intercept $\left(\pi_{0}\right)$} \\
\hline Intercept (at 6 months) & $24.07^{\star \star \star}$ & $23.90^{\star \star \star}$ \\
\hline Ever dropped out & & -1.60 \\
\hline Death & & -1.79 \\
\hline Intervention group & & $1.89^{\star \star}$ \\
\hline At-admission cognitive impairment & & $-5.66^{\star \star \star}$ \\
\hline Age & & $-0.10^{\star}$ \\
\hline Male & & 0.28 \\
\hline$\geq$ Primary school & & $3.51^{\star \star \star}$ \\
\hline \multicolumn{3}{|l|}{ For linear time slope $\left(\pi_{1}\right)$} \\
\hline Intercept & 0.008 & -0.06 \\
\hline Ever dropped out & & -0.25 \\
\hline Death & & $-0.35^{\star}$ \\
\hline Intervention group & & $0.30^{\star *}$ \\
\hline At-admission cognitive impairment & & $0.33^{\star \star}$ \\
\hline Age & & -0.01 \\
\hline Male & & -0.05 \\
\hline$\geq$ Primary school & & 0.11 \\
\hline \multicolumn{3}{|l|}{ For quadratic time slope $\left(\pi_{2}\right)$} \\
\hline Intercept & $-0.007^{\star \star}$ & $-0.01^{\star \star \star}$ \\
\hline Ever dropped out & & -0.02 \\
\hline Death & & $-0.03^{\star}$ \\
\hline Intervention group & & $-0.01^{\star \star}$ \\
\hline At-admission cognitive impairment & & $-0.02^{\star \star}$ \\
\hline Age & & -0.00 \\
\hline Male & & 0.002 \\
\hline$\geq$ Primary school & & -0.009 \\
\hline \multicolumn{3}{|l|}{ Random effect } \\
\hline Intercept & $26.42^{\star \star \star}$ & $9.16^{\star \star \star}$ \\
\hline Linear time slope & $0.16^{\star \star \star}$ & $0.12^{\star \star \star}$ \\
\hline Quadratic time slope & 0.000 & $0.00^{\star \star}$ \\
\hline Deviance & 3346 & 3142 \\
\hline Number of estimated parameters & 7 & 7 \\
\hline
\end{tabular}

Outcome variable is MMSE score.

${ }^{*} p<0.05,{ }^{* *} p<0.01,{ }^{* * *} p<0.001$. 